\title{
O uso do socioleto literário em três traduções de Great Expectations
}

\author{
The use of literary sociolect in \\ three translations of Great \\ Expectations
}

\author{
Mateus Roman Pamboukian*
}

Resumo: A partir de uma discussão sumária sobre os conceitos de socioleto literário e eye dialect (baseada em Lane-Mercier, Brett e Pym), este trabalho aborda o uso do socioleto literário no romance Great Expectations (1861) de Charles Dickens e compara soluções encontradas por três diferentes tradutores do romance, a saber: Armando de Morais, Charles Bernard-Derosne e Paulo Henriques Britto.

Palavras-chave: Tradução; Socioleto literário; Literatura Inglesa.

Abstract: Drawing on a brief discussion of the concepts of literary sociolect and eye dialect (based on Lane-Mercier, Brett and Pym), this paper addresses the use of literary sociolect in Charles Dickens' novel Great Expectations (1861) and compares the solutions found by three different translators of the novel, namely: Armando de Morais, Charles Bernard-Derosne and Paulo Henriques Britto.

Keywords: Translation; Literary Sociolect; English Literature.

\footnotetext{
* Doutorando em Letras pela Universidade de São Paulo (LETRA/FFLCH). E-mail: mateus.pamboukian@usp.br 


\section{Considerações iniciais}

Sabe-se que a representação de variantes dialetais na literatura existe pelo menos desde a antiga comédia grega (COLVIN 1995: 35). No entanto, embora se trate de um recurso há muito utilizado, o tema continua suscitando discussões no campo dos estudos da tradução. Lane-Mercier chama tais representações de literary sociolects, que define como

[...] a textual representation of "non-standard" speech patterns that manifest both the socio-cultural forces which have shaped the speaker's linguistic competence and the various socio-cultural groups to which the speaker belongs or has belonged. As a rule, these non-standard patterns appear in the direct discourse of one or several characters, whose phonetic, syntactic, lexical and/or semantic configurations are thus set off, usually (but certainly not always) in a negative or derogatory mode, from socially "neutral", linguistically "correct" discourse of the narrator, and, as the case may be, of other characters. ${ }^{1}$ (LANE-MERCIER 1997: 46)

Tais representações (cujo caráter artificioso é importante não perder de vista) constituiriam, quando não "uma zona bem definida de intraduzibilidade", ao menos um "componente textual resistente, opaco, cuja tradução é carregada com um sem-número de perdas e ganhos semânticos" (Mercier 1997: 46, tradução nossa). Ao longo do mesmo artigo, Lane-Mercier discute alguns dos riscos em que incorre o tradutor que se aventure a traduzir socioletos literários: além de eventuais perdas ou acréscimos de dimensões de significado que determinadas variantes podem ter em determinados contextos, soluções canhestras para a tradução de socioletos poderiam acarretar uma tradução etnocêntrica, em que o estrangeiro seria representado de forma pejorativa.

Embora se trate de tarefa bastante delicada, algumas estratégias costumam ser empregadas de forma mais ou menos sistemática. Morini (apud BRETT 2009: 50) distingue algumas delas:

\footnotetext{
1 “Uma representação textual de padrões de discurso 'desviantes' que manifestam tanto as forças socioculturais que modelaram a competência linguística do falante quanto os diversos grupos socioculturais aos quais o falante pertence ou pertenceu. Via de regra, tais padrões desviantes aparecem no discurso direto de uma ou várias personagens, cujas configurações fonéticas, sintáticas, lexicais e/ou semânticas são, assim, deslocadas, normalmente (mas não sempre) de modo negativo ou pejorativo, do discurso socialmente 'neutro', linguisticamente 'correto' do narrador e, conforme o caso, de outras personagens". (Tradução nossa)
} 
Whenever two or more variants of the same language inhabit the same textual space, the translator can: 1) write his target text in the standard version of the target language; 2) employ two or more variants of the target language; 3) translate one of the variants by a non-standard (incorrect, popular) variant of the target language. ${ }^{2}$

Uma quarta estratégia possível também assinalada por Morini seria a criação de uma língua-alvo sintética, por meio de pequenas modificações ou incorreções (apud BRETT 2009: 51). Tal expediente permitiria preservar a marca da variante sem o risco de produzir uma fala estereotipada ou ofensiva para alguém que identifique uma representação pejorativa de seu socioleto. Nesse sentido, é pertinente a observação de Anthony Pym a respeito de por que traduzir marcadores de variantes:

The answer to our original question is now deceptively easy. When translators are confronted with the markers of a variety, the thing to be rendered is not the source-text variety (such things, by definition, do not move, and translation is in any case the replacement of the base sourcetext variety, by definition). The thing to be rendered is the variation, the syntagmatic alteration of distance, the relative deviation from the norm. If those shifts can be rendered, as is usually the case, then the markers may be said to have been translated, and no complaint should ensue. ${ }^{3}$ (PYM 2000: 72)

\section{Eye dialect}

Uma forma frequente de representar variantes não usuais em textos ficcionais é o que se chama de eye dialect, que consiste em marcações ortográficas de um registro que desvia do padrão. Segundo Brett (2009: 49), o

\footnotetext{
2 "Sempre que duas ou mais variantes de uma mesma língua habitarem o mesmo espaço textual, o tradutor pode: 1) escrever seu texto-alvo na versão padrão da língua-alvo; 2) empregar duas ou mais variantes da língua alvo; 3 ) traduzir uma das variantes por uma variante não-padrão (incorreta, popular) da língua-alvo." (Tradução livre.)

3 "A resposta à nossa pergunta original agora é enganosamente fácil. Quando tradutores são confrontados com marcadores de uma variante, a coisa a ser vertida não é a variante do texto-fonte (tais coisas, por definição, não se movem, e a tradução é, em todo caso, a substituição da variante de base do texto-fonte, por definição). A coisa a verter é a variante, a alteração sintagmática da distância, o desvio relativo da norma. Se tais deslocamentos puderem ser vertidos, como geralmente se dá, pode-se dizer que os marcadores terão sido traduzidos e nenhuma queixa deve ocorrer." (Tradução livre.)
} 
termo foi cunhado por George P. Krapp em 1925, e a explicação repousaria no fato de que, diferentemente do que se dá com os socioletos em sentido estrito, que distinguimos por traços auditivos, o socioleto literário se torna patente por meio de sinais visuais. Ainda segundo Brett (2009:49), o termo foi inicialmente empregado apenas para descrever o uso de grafias alternativas para palavras em língua inglesa (enuff para enough, animulz para animals etc), mas posteriormente passou a ser empregado de forma mais ampla, abrangendo qualquer variação ortográfica que indique pronúncias ou sotaques específicos.

Tal recurso gráfico é particularmente comum na literatura de língua inglesa, já sendo comum nas épocas de Shakespeare e Chaucer com propósitos cômicos (PUKkARI 2015: 3). Mais recentemente, um dos autores que se notabilizaram pelo uso de eye dialect e pela inclusão do dialeto cockney em suas obras é Charles Dickens. Veja-se, por exemplo, o trecho da fala de Gamfield, personagem do romance Oliver Twist:

'That's acause they damped the straw afore they lit it in the chimbley to make 'em come down again,' said Gamfield; 'that's all smoke, and no blaze; vereas smoke ain't o' no use at all in making a boy come down, for it only sinds him to sleep, and that's wot he likes. Boys is wery obstinit, and wery lazy, Gen'l'men, and there's nothink like a good hot blaze to make 'em come down vith a run. It's humane too, gen'l'men, acause, even if they've stuck in the chimbley, roasting their feet makes 'em struggle to hextricate theirselves' (apud BRETT 2009: 52)

Aqui, há exemplos de vários tipos de desvios da norma: desvios de natureza fonética (sons de / $/ \mathrm{V}$ que se tornam / $\mathrm{w} /$ e vice-versa, como em "wery" e "vith"; inclusão de uma aspiração onde não existe, como em "hextricate" etc), exemplos do eye dialect em seu sentido estrito ("wot", "obstinit"); mesmo francas corruptelas de palavras inglesas ("nothink", “chimbley"). Conforme Brett ressalta (BRETT 2009: 53), o recurso tem valor significativo para a caracterização da personagem, contribuindo para que o enxerguemos como um sujeito pouco educado e insensível. No entanto, conforme demonstram os exemplos do próprio Brett, tais marcas dialetais do discurso das personagens são frequentemente apagadas em traduções. 
Observe-se, em um exemplo adicional, o mesmo trecho traduzido para o português por Antônio Ruas:

- É porque umedecem a palha antes de acendê-la na chaminé quando querem descer - explicou o Sr. Gamfield. - É tudo fumo e nenhuma chama; ora, o fumo de nada serve para fazer descer um rapaz, porque apenas o faz dormir e é disso que ele gosta. Os rapazes são muito teimosos e muito preguiçosos, cavalheiros, e não há nada como uma boa chama quente para fazê-los vir abaixo bem depressa. É também humano, cavalheiros, porque, se eles ficam colados à chaminé, queimam os pés, e isso os faz lutar para se desvencilharem. (DICKENS 197?: 29-30.)

Como se pode ver, todas as marcas dialetais são apagadas, e o tradutor substitui o inglês crivado de desvios da norma do texto original por um português rigorosamente adequado à gramática normativa. Muito já se escreveu sobre as diretrizes editoriais e ideológicas que ensejaram e ainda ensejam esse tipo de procedimento no Brasil. Conforme aponta John Milton (1996: 52),

Right up until recent years, translations of classic novels into Portuguese refused to contemplate any kind of sub-standard language. All slang and sub-standard language was translated into correct Portuguese, thus losing much of the original effect. [...] I would say that the major reason for this is the continuation of the mentality of belles infideles right into the second half of the twentieth century. ${ }^{4}$

\section{0 uso de variantes em Great Expectations}

O exemplo anterior de Dickens não foi fortuito, uma vez que trabalharemos com a presença do socioleto literário em um de seus principais romances: Great Expectations (Grandes esperanças), de 1861.

\footnotetext{
4 "Até recentemente, traduções de romances clássicos para o português se negaram a incluir qualquer tipo de linguagem desviante do padrão. Todas as gírias e toda linguagem desviante do padrão eram traduzidas para português correto, perdendo, assim, muito do efeito original. Eu diria que o motivo principal disso é a continuação da mentalidade das belles infidèles até a segunda metade do século vinte." (Tradução livre.)
} 
Um dos últimos livros de Dickens, Great Expectations é um de seus poucos romances quase inteiramente narrados em primeira pessoa. Conforme se pode notar pelas primeiras linhas do livro, o narrador-personagem Philip Pirrip (Pip) utiliza um inglês bastante adequado ao padrão normativo, que também podemos identificar nas falas de personagens como Herbert, Estella ou Miss Havisham:

My father's family name being Pirrip, and my Christian name Philip, my infant tongue could make of both names nothing longer or more explicit than Pip. So, I called myself Pip, and came to be called Pip. I give Pirrip as my father's family name, on the authority of his tombstone and my sister-Mrs. Joe Gargery, who married the blacksmith. As I never saw my father or my mother, and never saw any likeness of either of them (for their days were long before the days of photographs), my first fancies regarding what they were like, were unreasonably derived from their tombstones. The shape of the letters on my father's gave me an odd idea that he was a square, stout, dark man, with curly black hair. From the character and turn of the inscription, "Also Georgiana Wife of the Above," I drew a childish conclusion that my mother was freckled and sickly. To five little stone lozenges, each about a foot and a half long, which were arranged in a neat row beside their grave, and were sacred to the memory of five little brothers of mine-who gave up trying to get a living exceedingly early in that universal struggle-l am indebted for a belief I religiously entertained that they had all been born on their backs with their hands in their trousers-pockets, and had never taken them out in this state of existence. (DICKENS 1929: 1)

Para Pukkari (2015:19), é inverossímil a ausência de desvios na fala de uma personagem de origens modestas como Pip (em contraste com outras personagens do romance de mesmo estrato social), um órfão educado por um ferreiro. No entanto, há um momento específico do livro em que o contraste entre os falares de Pip e Estella é mobilizado:

The difference between Estella's and Pip's speech is only apparent in the narration, as Pip recalls calling knaves by their then improper dialect word jack and being laughed at for it (GE, p. 92). This particular locution represents to Pip his low-class status on society, and in part plants the seed of dissatisfaction in his circumstances in his mind. "I was a common labouring-boy; that my hands were coarse; that my boots were thick; that I had fallen into a despicable habit of 
calling knaves Jacks; that I was much more ignorant than I had considered myself last night, and generally that I was in a low-lived bad way' ( $p$. 94). Here a single dialect word seems to highlight the social difference between Estella and Pip. His love for Estella and urge to become worthy of her are mainly what drives Pip into trying to better himself. ${ }^{5}$ (PUKKARI 2015: 19).

De qualquer forma, o inglês do narrador-personagem se contrasta de forma evidente com a de outras personagens. Isto já fica claro na famosa primeira cena do romance, em que Pip é acossado no cemitério pelo bandido recém-escapado das galés Abel Magwitch, que mais tarde se tornará o seu benfeitor misterioso e viabilizará sua ascensão social:

"You young dog," said the man, licking his lips, "what fat cheeks you ha' got."

I believe they were fat, though I was at that time undersized, for my years, and not strong.

"Darn Me if I couldn't eat 'em," said the man, with a threatening shake of his head, "and if I han't half a mind to't!"

I earnestly expressed my hope that he wouldn't, and held tighter to the tombstone on which he had put me; partly, to keep myself upon it; partly, to keep myself from crying.

"Now lookee here!" said the man. "Where's your mother?"

"There, sir!" said I.

He started, made a short run, and stopped and looked over his shoulder.

"There, sir!" I timidly explained. "Also Georgiana. That's my mother."

"Oh!" said he, coming back. "And is that your father alonger your mother?"

"Yes, sir," said I; "him too; late of this parish."

"Ha!" he muttered then, considering. "Who d'ye live withsupposin' you're kindly let to live, which I han't made up my mind about?"

"My sister, sir-Mrs. Joe Gargery-wife of Joe Gargery, the blacksmith, sir." (DICKENS 1929: 3)

\footnotetext{
5“'A diferença entre o discurso de Estella e Pip só aparece na narração quando Pip se lembra de chamar os valetes (knaves) por seu termo dialetal incorreto jack, e de ser alvo de risadas por isso (GE, p. 92). Esta locução em especial the faz apreender seu baixo status na sociedade, em parte plantando as sementes da insatisfação com suas circunstâncias em sua mente. 'Eu era um trabalhadorzinho vulgar; que minhas mãos eram grosseiras, que minhas botas eram pesadas; que eu adquirira o hábito desprezível de chamar os valetes de jotas; que eu era muito mais ignorante do que julgava ser na véspera, e, de modo geral, que minha vida era muito vil e má' (p. 94). Aqui, uma simples palavra de dialeto parece destacar a diferença social entre Estella e Pip. Seu amor por Estella e seu ímpeto em se tornar digno dela são os principais motivos de sua tentativa de se tornar melhor." (Tradução nossa)
} 
Conforme se pode ver, o discurso de Magwitch é marcado por desvios (vide destaques em negrito) que inexistem na fala de Pip. Analisando as marcas dialetais de Magwitch, Pukkari (2015: 16), destaca que, embora apresente desvios morfossintáticos, como erros de concordância, os principais desvios da fala de Magwitch são assinalados por abreviações e omissões de letras, de sorte que os desvios da norma são menos bruscos do que os que se observam nas falas de outras personagens, como Joe Gargery. Com efeito, o ferreiro é provavelmente a personagem do romance em cuja fala observamos a presença mais nítida tanto do eye dialect em sentido estrito quanto de desvios gerais do inglês normativo:

I meantersay, you two gentlemen - which I hope as you get your elths in this close spot? For the present may be a werry good inn, according to London opinions," said Joe, confidentially, "and I believe its character do stand; but I wouldn't keep a pig in it myself - not in the case that I wished him to fatten wholesome and to eat with a meller flavour on him. (DICKENS apud PUKKARI 2015:15)

Pukkari cita outra passagem bastante significativa em que Joe explica a Pip os motivos pelos quais não pôde estudar. Seu baixo letramento transparece por meio de desvios sintáticos, ortográficos, fonológicos:

My father, Pip, he were given to drink, and when he were overtook with drink, he hammered away at my mother, most onmerciful. It were a'most the only hammering he did, indeed, 'xcepting at myself. And he hammered at me with a wigour only to be equalled by the wigour with which he didn't hammer at his anwil. - You're alistening and understanding, Pip? (DICKENS apud PUKKARI 2015:15)

Algumas marcas de dialeto aparecem com menor intensidade na fala de outras personagens, como a irmã de Pip, Mrs. Gargery:

"Where have you been, you young monkey?" said Mrs. Joe, stamping her foot. "Tell me directly what you've been doing to wear me away with fret and fright and worrit, or l'd have you out of that corner if you was fifty Pips, and he was five hundred Gargerys." 
"I have only been to the churchyard," said I, from my stool, crying and rubbing myself.

"Churchyard!" repeated my sister. "If it warn't for me you'd have been to the churchyard long ago, and stayed there. Who brought you up by hand?" (DICKENS 1929: 8)

Tendo brevemente comentado a presença do socioleto literário ao longo do romance, passamos finalmente à análise das soluções de algumas das traduções de Great Expectations. Para tanto, atentaremos especialmente para exemplos traduzidos das falas das personagens Joe Gargery e Abel Magwitch.

\section{Les Grandes Espérances: a tradução de Bernard-Derosne}

A primeira tradução de Great Expectations cujas soluções analisaremos é a tradução francesa de Charles Bernard-Derosne, publicada em 1896 pela Hachette. Comecemos comparando o texto original do diálogo entre Pip e Magwitch (comentado na seção anterior):

\begin{tabular}{|c|c|}
\hline $\begin{array}{l}\text { "You young dog," said the man, licking } \\
\text { his lips, "what fat cheeks you ha' got." } \\
\text { I believe they were fat, though I was at }\end{array}$ & $\begin{array}{l}\text { "Mon jeune gaillard, dit l'homme, en } \\
\text { se léchant les lèvres, tu as des joues } \\
\text { bien grasses." }\end{array}$ \\
\hline $\begin{array}{l}\text { that time undersized, for my years, and } \\
\text { not strong. }\end{array}$ & $\begin{array}{l}\text { Je crois qu'effectivement mes joues } \\
\text { étaient grasses, bien que je fusse resté }\end{array}$ \\
\hline $\begin{array}{l}\text { "Darn Me if I couldn't eat 'em," said the } \\
\text { man, with a threatening shake of his } \\
\text { head, "and if I han't half a mind to't!" }\end{array}$ & $\begin{array}{l}\text { petit et faible pour mon âge. } \\
\text { « Du diable si je ne les mangerais pas! } \\
\text { dit l'homme en faisant un signe de tête }\end{array}$ \\
\hline $\begin{array}{l}\text { I earnestly expressed my hope that he } \\
\text { wouldn't, and held tighter to the } \\
\text { tombstone on which he had put me; } \\
\text { partly, to keep myself upon it; partly, } \\
\text { to keep myself from crying. }\end{array}$ & $\begin{array}{l}\text { menaçant, je crois même que j'en ai } \\
\text { quelque envie. " } \\
\text { J'exprimai l'espoir qu'il n'en } \\
\text { ferait rien, et je me cramponnai plus } \\
\text { solidement à la pierre sur laquelle il }\end{array}$ \\
\hline $\begin{array}{l}\text { "Now lookee here!" said the man. } \\
\text { "Where's your mother?" }\end{array}$ & $\begin{array}{l}\text { m'avait placé, autant pour m'y tenir en } \\
\text { équilibre que pour m'empêcher de }\end{array}$ \\
\hline $\begin{array}{l}\text { "There, sir!" said l. } \\
\text { He started, made a short run, and } \\
\text { stopped and looked over his shoulder. }\end{array}$ & $\begin{array}{l}\text { crier. } \\
\text { «Allons, dit l'homme, parle! où } \\
\text { est ta mère? }\end{array}$ \\
\hline $\begin{array}{l}\text { "There, sir!" I timidly explained. "Also } \\
\text { Georgiana. That's my mother." }\end{array}$ & $\begin{array}{l}\text { - Là, monsieur! » répondis-je. } \\
\text { Il fit un mouvement, puis quelqu }\end{array}$ \\
\hline "Oh!" said he, coming back. "And is that & essus son épaule. \\
\hline
\end{tabular}


your father alonger your mother?"

"Yes, sir," said I; "him too; late of this parish."

"Ha!" he muttered then, considering.

"Who d'ye live with-supposin' you're kindly let to live, which I han't made up my mind about?"

"My sister, sir-Mrs. Joe Gargery-wife of Joe Gargery, the blacksmith, sir."
« Là, monsieur!

repris-je

timidement en montrant la tombe.

Aussi Georgiana. C'est ma mère!

- Oh! dit-il en revenant, et c'est ton père qui est là étendu à côté de ta mère?

- Oui, monsieur, dis-je, c'est lui, défunt de cette paroisse.

- Ah! murmura-t-il en réfléchissant, avec qui demeures-tu, en supposant qu'on te laisse demeurer quelque part, ce dont je ne suis pas certain?

- Avec ma sour, monsieur... Mrs Joe Gargery, la femme de Joe Gargery, le forgeron, monsieur.

(DICKENS 1889: 4)

Como se pode notar, desaparecem no texto em francês as indicações gráficas (em negrito) da presença de variante, presentes no original tanto na forma de palavras grafadas de forma errada (“lookee", "alonger”) quanto na de abreviações e apócopes (“han't”, “supposin'“, “d'ye”, “'em”, “to't”), exemplos de eye dialect em sentido estrito. Talvez isso se possa explicar pelo fato de que, diferentemente da tradição da prosa inglesa, em que tais recursos gráficos abundam em diversos autores canônicos, é mais raro encontrá-los na prosa francesa: na literatura francesa coetânea a Dickens, mesmo personagens representantes de baixos estratos sociais (pense-se, por exemplo, nos mineiros do Germinal, em Fantine de Les Misérables, em Dussardier de Éducation Sentimentale) falam francês correto e sem desvios ortográficos.

Passemos para um trecho do segundo capítulo do livro, em que Joe Gargery previne Pip da iminência de uma surra:

"She sot down," said Joe, "and she got up, and she made a grab at Tickler, and she Ram-paged out. That's what she did," said Joe, slowly clearing the fire between the lower bars with the poker, and looking at it: "she Ram-paged out Pip."

"Has she been gone long, Joe?" I always sortie, Joe? dis-je, car je le traitais treated him as a larger species of child, toujours comme un enfant, et le 
and as no more than my equal.

"Well," said Joe, glancing up at the Dutch clock, "she's been on the Rampage, this last spell, about five minutes, Pip. She's a coming! Get behind the door, old chap, and have the jack-towel betwixt you." considérais comme mon égal.

- Hem ! dit Joe en regardant le coucou hollandais, il y a bien cing minutes qu'elle est partie en fureur... mon petit Pip. Elle revient ! ... Cachetoi derrière la porte, mon petit Pip, et rabats l'essuie-mains sur toi. »

(DICKENS 1929: 7)

(DICKENS 1889: 11)

Destacamos, em negrito, algumas marcas de dialeto na fala de Gargery: eye dialect ("she sot down" em vez de "sat down"; "Ram-page em vez de rampage"), o uso da forma dialetal "betwixt" no lugar do padrão "between" e o uso da forma gerundiva "she's a coming”. A tradução francesa não só apresenta casos de má tradução (e.g., “made a grab at Tickler”, "agarrou Tickler”, traduzido como "elle parlait à Tickler”, “ela falava com Tickler”) como apaga completamente as marcas dialetais da fala de Joe.

Passemos para um trecho do capítulo 42 , muito rico para a análise por se tratar de um capítulo quase inteiramente narrado por Abel Magwitch. No trecho a seguir, Magwitch conta o momento do julgamento que o condenou ao trabalho forçado vitalício nas galés:

\begin{abstract}
And when it come to character, warn't it Compeyson as had been to school, and warn't it his schoolfellows as was in this position and in that, and warn't it him as had been know'd by witnesses in such clubs and societies, and nowt to his disadvantage?

And warn't it me as had been tried afore, and as had been know'd up hill and down dale in Bridewells and LockUps?
\end{abstract}

And when it comes to speech-making, warn't it Compeyson as could speak to 'em wi' his face dropping every now and then into his white pockethandkercher-ah! and wi' verses in his speech, too-and warn't it me as could only say, 'Gentlemen, this man at my side is a most precious rascal'?

(DICKENS 1929: 365)
«Et ainsi de suite, et quand on arriva aux antécédents, il se trouva que Compeyson avait été en pension, que ses camarades de pension étaient dans telle ou telle position; plusieurs témoins l'avaient connu au club et dans le monde, et n'avaient que de bons renseignements à donner sur lui.

«Quant à moi, j’étais en récidive et l'on m'avait vu constamment par voies et chemins, dans les maisons de correction et sous clef.

«Quand vint le moment de parler aux juges, qui donc, sinon Compeyson, leur parla, en laissant retomber de temps en temps son visage dans son mouchoir blanc, et avec des vers dans son discours encore! Moi, je pus seulement dire :

«- Messieurs, cet homme, qui est à côté de moi, est le plus fameux scélérat... »

(DICKENS 1889: 160) 
A fala da personagem no texto original é fortemente marcada por elementos dialetais: além das habituais contrações e de casos de eye dialect ("nowt" em vez de "naught"), há o emprego sistemático de as como conjunção integrante (onde se esperaria “that"), desvios de concordância ("when it come"), corruptelas ("handkercher" em vez de "handkerchief") e formas verbais alternativas ("warn't" no lugar de "wasn't"; “know'd" no lugar de "knew" etc.).

A tradução do trecho por Bernard-Derosne é quase irreconhecível: não só apaga inteiramente todas as marcas dialetais elencadas, como também incorre mais uma vez em erros semânticos: por duas vezes traduz "when it comes" com um sentido temporal equivocado ("Quand on arriva aux antecedents[...]"; "Quand vint le moment de parler aux juges[...]”), o que compromete todo o sentido do resto. Além disso, arborescências sintáticas como a repetição da pergunta retórica marcada por "warn't it..." do texto original são completamente suprimidas. Aplicando sumariamente a clássica relação de deformações bermanianas ${ }^{6}$ (BERMAN 2007: 48-61), só neste trecho podemos identificar a ocorrência de pelo menos quatro: 1) racionalização; 2) enobrecimento; 3) homogeneização; e 4) apagamento de superposição de línguas.

\section{Grandes esperanças: a tradução de Armando de Morais}

A segunda tradução com que trabalharemos é uma tradução portuguesa feita para o clube do livro Círculo de Leitores. Posteriormente, essa tradução foi cedida para o Círculo do Livro, tendo circulado no Brasil nos anos 80. A título de conveniência, trabalharemos com alguns dos mesmos trechos que analisamos na tradução de Bernard-Derosne.

\footnotetext{
${ }^{6}$ Trata-se de uma famosa lista de treze "tendências deformadoras" elencadas por Antoine Berman na obra citada, a saber: 1) racionalização; 2) clarificação; 3) alongamento; 4) enobrecimento; 5) empobrecimento qualitativo; 6) empobrecimento quantitativo; 7) homogeneização; 8) destruição dos ritmos; 9) destruição das redes significantes subjacentes; 10) destruição dos sistematismos; 11) destruição ou exotização das redes de linguagens vernaculares; 12) destruição das locuções; 13) apagamento das superposições de línguas.
} 
"You young dog," said the man, licking his lips, "what fat cheeks you ha' got."

I believe they were fat, though I was at that time undersized, for my years, and not strong.

"Darn Me if I couldn't eat 'em," said the man, with a threatening shake of his head, "and if I han't half a mind to't!"

I earnestly expressed my hope that he wouldn't, and held tighter to the tombstone on which he had put me; partly, to keep myself upon it; partly, to keep myself from crying.

"Now lookee here!" said the man. "Where's your mother?"

"There, sir!" said I.

He started, made a short run, and stopped and looked over his shoulder.

"There, sir!" I timidly explained. "Also Georgiana. That's my mother."

"Oh!" said he, coming back. "And is that your father alonger your mother?"

"Yes, sir," said I; "him too; late of this parish."

"Ha!" he muttered then, considering.

"Who d'ye live with-supposin' you're kindly let to live, which I han't made up my mind about?"

"My sister, sir-Mrs. Joe Gargery-wife of Joe Gargery, the blacksmith, sir."
“- Eh, meu cachorrinho - rosnou lambendo os beiços. - Que cara gorda tu tens!

Suponho que era gorda, de fato, se bem que eu, nessa altura, estivesse insuficientemente crescido para a minha idade e não fosse forte.

- Diabos me levem se não era capaz de a comer! - continuou com um ameaçador aceno de cabeça. - E olha que estou mesmo ficando com vontade!

Exprimi, com toda a seriedade, a minha esperança de que ele não fizesse tal coisa e colei-me ainda mais à pedra da capa em que me havia posto, em parte para me segurar, em parte também para evitar gritar.

- Olha - disse o homem. - Onde é que está a tua mãe?

- Ali, meu senhor! - respondi.

Ele se afastou, andou um pouco, parou e virou a cabeça para mim,

- É ali, meu senhor! - expliquei timidamente. Também Georgiana. É a minha mãe.

- Oh! - exclamou, voltando para trás. $E$ aquele que está ao lado é o teu pai?

- É, sim, senhor - disse eu. - Também. Falecido nesta paróquia.

- Ah! - resmungou pensativamente. Com quem é que tu vives, então! Isso supondo que concedo a mercê de te deixar viver, que é coisa que ainda não resolvi.

- Com minha irmã, meu senhor! A Sra. Joe Gargery, casada com Joe Gargery, o ferreiro, meu senhor."

(DICKENS 198?: 7)

Assim como observamos na tradução de Bernard-Derosne, as marcas dialetais da fala de Magwitch são todas apagadas. Morais substitui a fala áspera do criminoso, importante para sua caracterização, por um registro de português distintamente elevado, incorrendo em um enobrecimento ainda mais drástico do que o que ocorre na tradução francesa. Recorde-se a 
tradução do trecho de Oliver Twist (também do Círculo do Livro) mencionada mais cedo: fenômeno semelhante pode ser observado na fala da personagem Gamfield. Passemos, agora, para o diálogo entre Joe e Pip no segundo capítulo:

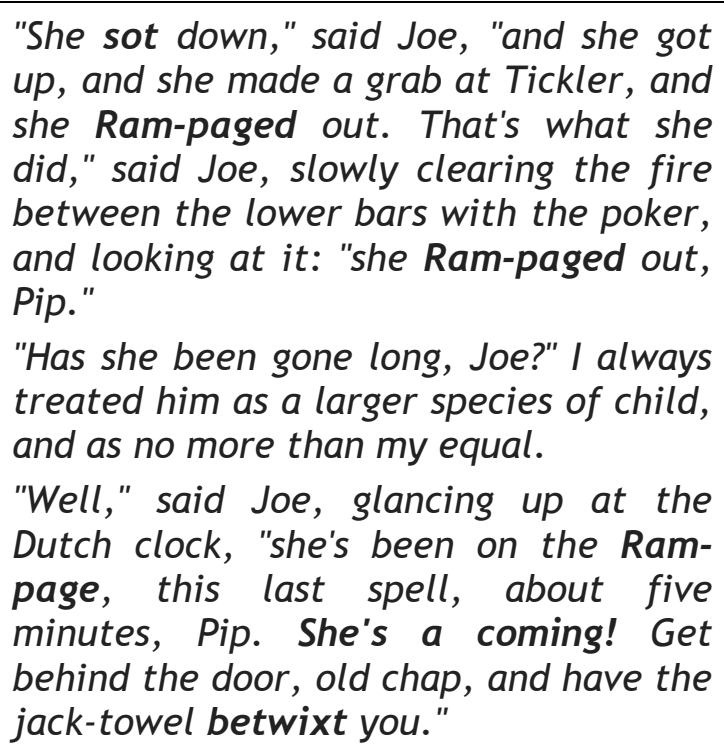
up, and she made a grab at Tickler, and she Ram-paged out. That's what she did," said Joe, slowly clearing the fire between the lower bars with the poker, and looking at it: "she Ram-paged out, Pip."

"Has she been gone long, Joe?" I always treated him as a larger species of child, and as no more than my equal.

"Well," said Joe, glancing up at the Dutch clock, "she's been on the Rampage, this last spell, about five minutes, Pip. She's a coming! Get behind the door, old chap, and have the jack-towel betwixt you."

“- Ela se sentou e se levantou, tomou o código e rompeu pela porta afora. Foi assim que ela fez - disse Joe, mexendo vagarosamente 0 fogo, pela parte inferior das grades, com o atiçador, e olhando para ele. - Rompeu pela porta afora, Pip.

- Há muito tempo, Joe? - Era como a uma espécie de criança mais crescida e sempre como meu igual que eu o tratava.

- Olha, disse Joe, relanceando o olhar para o relógio holandês -, rompeu pela porta afora há cerca de cinco minutos, Pip. E aí vem ela! Vai para trás da porta, meu velho, e enrola a toalha grossa no corpo."

(DICKENS 1929: 11)

(DICKENS 198?: 11)

Também aqui observamos um apagamento das marcas dialetais e um enobrecimento do registro da fala da personagem, a que Armando Morais empresta uma dicção que pouco se distingue da fala de Pip. Conforme temos discutido neste trabalho, tal expediente homogeneíza o texto, destruindo nuances importantes do estilo. Ao fim e ao cabo, a tais projetos tradutórios parece subjazer uma concepção que reduz a tradução da prosa à transposição do que está expresso no plano referencial da linguagem - aquilo que Walter Benjamin, em seu clássico ensaio "A tarefa do tradutor”, chamaria de "uma transmissão inexata de um conteúdo inessencial” (apud TÁPIA 2012: 290).

Em comparação com a tradução francesa do mesmo trecho, em que também ocorre homogeneização (talvez em menor grau), a tradução de Morais tem desvantagens evidentes: além da questão do apagamento das variantes, a escolha de traduzir o apelido do pedaço de pau com que a irmã 
de Pip o surrava ("Tickler”) por “código” não parece se justificar senão por uma compreensão equivocada do original.

Passemos, por fim, ao trecho da narração de Magwitch do capítulo 42:

And when it come to character, E quando se tratou das qualidades de warn't it Compeyson as had been to cada um, não era então Compeyson school, and warn't it his que tinha estudos, e que tinha schoolfellows as was in this position condiscípulos nesta e naquela and in that, and warn't it him as posição, e não era ele que tinha sido had been know'd by witnesses in visto neste e naquele clube e nesta e such clubs and societies, and nowt naquela companhia, e tudo para to his disadvantage? And warn't it vantagem sua? E não era eu que já me as had been tried afore, and as tinha sido julgado e visto por montes had been know'd up hill and down dale in Bridewells and Lock-Ups? And when it comes to speech-making, warn't it Compeyson as could speak to 'em wi' his face dropping every now and then into his white pockethandkercher-ah! and wi' verses in his speech, too-and warn't it me as could only say, 'Gentlemen, this man at my side is a most precious rascal'?

e vales, em casas de correção e calabouços? E quando se tratou de falar, não foi Compeyson quem falou, escondendo o rosto de vez em quando no seu lenço branco... ah! E com versos no discurso também!, ,, e não fui eu quem apenas sabia dizer: "Senhores, este homem aqui a meu lado é um patife dos mais requintados!'

(DICKENS 1929: 365)

(DICKENS 198?: 371)

Se nos ativermos apenas ao plano referencial, as opções de Morais, desta vez, apresentam menos problemas do que as de Bernard-Derosne. No entanto, o apagamento das marcas dialetais é gritante. Já se pontuou aqui como o uso do dialeto é elemento importante para a caracterização das personagens nos romances de Dickens. Aqui, o proscrito ríspido e inculto fala como um lorde, o que é ainda mais incoerente se se considera o teor do excerto: Magwitch relata justamente os tratamentos diversos dispensados pela justiça a ele, homem de origem humilde e pouca articulação, e Compeyson, homem de origem social mais alta que dominava usos da língua vedados a ele. Muito antes da sociolinguística moderna, Dickens já parecia ter consciência da dimensão de poder conferido pelo domínio de certos registros da língua. Para o leitor brasileiro, a insegurança linguística de Magwitch talvez lembre o Fabiano de Vidas Secas, que "admirava as palavras compridas 
e difíceis da gente da cidade, tentava reproduzir algumas, em vão, mas sabia que elas eram inúteis e talvez perigosas”. (RAmOs 2011: 20)

Para finalizar nossas considerações a respeito da tradução de Morais, é possível traçarmos uma hipótese: assim como parece ter sido praxe editorial no Brasil ditatorial expurgar romances de elementos considerados impróprios para a "grande literatura" ao traduzi-los (MILTON 1996: passim), é plausível assumir que algo semelhante tenha se dado em Portugal durante 0 salazarismo (1933-1974), regime fascista marcado por lemas como "Deus, Pátria e Família".

\title{
6. Grandes esperanças: a tradução de Paulo Henriques Britto
}

A última tradução com que lidaremos é a tradução de Paulo Henriques Britto, publicada em 2012 pela Companhia das Letras. Antes de lidarmos propriamente com o texto, parece-nos pertinente evocar algumas ideias teóricas do próprio Britto a respeito da tradução. Em A tradução literária (2012: 67), está dito o seguinte:

\begin{abstract}
A questão que se coloca para o tradutor contemporâneo, interessado em produzir uma versão que respeite as características do original, é determinar até que ponto é possível reproduzir essas características na língua meta, com as especificidades e limitações dessa língua meta. Neste ponto, um dos princípios fundamentais da tradução literária, enunciado pelo já citado Meschonnic, deve ser levado em conta: traduzir o marcado pelo marcado, o não marcado pelo não marcado.
\end{abstract}

A título de exemplo, Britto propõe uma tradução para uma fala da personagem Alfred Jingle, de Pickwick Papers (outro romance de Dickens). A principal característica das falas de Jingle, que as distinguem das falas das outras personagens, é a fragmentação sintática, assinalada graficamente pela profusão de travessões: 


\begin{abstract}
Terrible place - dangerous work - other day - five children - mother - tall lady, eating sandwiches - forgot the arch crash - knock - children look round mother's head off - sandwich in her hand - no mouth to put in - head of a family off - shocking, shocking!
\end{abstract}

\begin{abstract}
Lugar terrível - trabalho perigoso - no outro dia - cinco crianças - mãe senhora alta, comendo sanduíchesesqueceu-se do arco - plaft - ploque crianças olham para o lado - cabeça da mãe arrancada - sanduíche na mão sem boca onde enfiá-lo - família perdeu a cabeça - chocante, chocante!
\end{abstract}

(DICKENS apud BRITTO 2012: 68)

(BRITTO 2012: 68)

Haja vista o caráter marcado da fragmentação sintática das falas de Jingle, sua violação implicaria uma deformação:

\begin{abstract}
Ora, um tradutor que vertesse essa passagem em frases de sintaxe completa, com sujeito, verbo e predicado, artigos e conjunções [...], estaria 'desmarcando' o original, despindo-o de sua estranheza, e desse modo violaria o princípio de Meschonnic. A transgressão oposta seria a de um tradutor que tomasse a fala do protagonista, o sr. Pickwick, que é perfeitamente convencional, e a fragmentasse de modo a assemelhá-la à fala de Jingle: nesse caso, diríamos que o tradutor estaria traduzindo o não marcado pelo marcado. (BRITTO 2012: 68)
\end{abstract}

Assim sendo, passemos para a análise a fim de averiguarmos em que medida as ideias teóricas de Britto tomam forma em sua prática tradutória.

\begin{tabular}{|c|c|}
\hline $\begin{array}{l}\text { "You young dog," said the man, licking } \\
\text { his lips, "what fat cheeks you ha' got." }\end{array}$ & $\begin{array}{l}\text { "Filhote de cachorro", disse o homem, } \\
\text { lambendo os beiços, "tuas bochecha é }\end{array}$ \\
\hline $\begin{array}{l}\text { I believe they were fat, though I was at } \\
\text { that time undersized, for my years, and }\end{array}$ & bem gorducha." \\
\hline $\begin{array}{l}\text { not strong. } \\
\text { "Darn Me if I couldn't eat 'em," said the } \\
\text { man, with a threatening shake of his } \\
\text { head, "and if I han't half a mind to't!" }\end{array}$ & $\begin{array}{l}\text { Creio que eram mesmo gordas, embora } \\
\text { na época eu fosse um menino pequeno } \\
\text { para minha idade, e nada forte. }\end{array}$ \\
\hline $\begin{array}{l}\text { I earnestly expressed my hope that he } \\
\text { wouldn't, and held tighter to the } \\
\text { tombstone on which he had put me; } \\
\text { partly, to keep myself upon it; partly, } \\
\text { to keep myself from crying. }\end{array}$ & $\begin{array}{l}\text { "Ora se eu não comia elas", disse o } \\
\text { homem, sacudindo a cabeça de modo } \\
\text { ameaçador, "e posso muito bem comer, } \\
\text { mesmo!" }\end{array}$ \\
\hline $\begin{array}{l}\text { "Now lookee here!" said the man. } \\
\text { "Where's your mother?" } \\
\text { "There, sir!" said I. } \\
\text { He started, made a short run, and }\end{array}$ & $\begin{array}{l}\text { Manifestei enfaticamente a esperança } \\
\text { de que ele não fizesse tal coisa, e } \\
\text { agarrei-me com mais força à lápide em } \\
\text { que ele me colocara; em parte para não }\end{array}$ \\
\hline
\end{tabular}


stopped and looked over his shoulder.

"There, sir!" I timidly explained. "Also

Georgiana. That's my mother."

"Oh!" said he, coming back. "And is that your father alonger your mother?"

"Yes, sir," said I; "him too; late of this parish."

"Ha!" he muttered then, considering. "Who d'ye live with-supposin' you're kindly let to live, which I han't made up my mind about?"

"My sister, sir-Mrs. Joe Gargery-wife of Joe Gargery, the blacksmith, sir." cair dela, em parte para não chorar.

"Escuta aqui!", disse o homem. "Que é da tua mãe?"

“Ali, senhor!", apontei.

Ele assustou-se, correu um pouco, parou e olhou para trás.

“Ali, senhor!", expliquei, tímido. "Também Georgiana. É a minha mãe."

“Ah!”, ele exclamou, voltando. "E aquele ali ao lado da tua mãe é o teu

pai?"

"Sim, senhor", respondi, "paroquiano de cá."

"Ah!", ele murmurou então, pensativo.

"Tu vives com quem - se é que eu vou ser bonzinho e te deixar viver, coisa que ainda não decidi?"

"Minha irmã, senhor - a senhora Joe

Gargery - mulher de Joe Gargery, o

ferreiro, senhor."

(DICKENS 2012: 35)

Aqui, conforme tentamos demonstrar pelos grifos em negrito, pela primeira vez nos deparamos com uma tradução que leva em conta a questão da variante. Diferentemente das traduções de Bernard-Derosne e Armando de Morais, em que Magwitch fala sem qualquer desvio gramatical, Britto introduz não só elementos coloquiais ("que é da tua mãe?") como solecismos ("se eu não comia elas") e erros de concordância ("tuas bochecha é bem gorda") bastante característicos do português brasileiro oral, assim logrando um êxito duplo: traduz o marcado pelo marcado e produz uma fala verossímil e orgânica em português. Prossigamos para o diálogo entre Pip e Joe no segundo capítulo.

"She sot down," said Joe, "and she got up, and she made a grab at Tickler, and she Ram-paged out. That's what she did," said Joe, slowly clearing the fire between the lower bars with the poker, and looking at it: "she Ram-paged out, Pip."

"Has she been gone long, Joe?" I always
"Ela sentou", disse Joe, "e levantou, e garrou no pau-de-cosca, e saiu espumando. Foi o que ela fez", disse Joe, lentamente abrindo espaço para o fogo entre as barras inferiores com o atiçador, e olhando para ele: "Saiu espumando, Pip." 
treated him as a larger species of child, and as no more than my equal.

"Well," said Joe, glancing up at the Dutch clock, "she's been on the Rampage, this last spell, about five minutes, Pip. She's a coming! Get behind the door, old chap, and have the jack-towel betwixt you."

(DICKENS 1929: 7)
“Ela já saiu há muito tempo, Joe?" Eu sempre o tratava como uma espécie maior de criança, e como um igual.

"Bom", ele respondeu, olhando de relance para o relógio alemão, "ela saiu espumando, da última vez, há coisa de cinco minuto, Pip. Lá vem ela! Te esconde atrás da porta, meu velho, e fica atrás da toalha rolante."

(DICKENS 2012: 56)

Também aqui observamos uma preocupação com a manutenção das marcas dialetais (vide negritos). Além de recursos como erros de concordância nominal (“cinco minuto”), Britto lança mão de um recurso gráfico parecido com o eye dialect de língua inglesa, marcando a pronúncia de determinadas palavras ("garrou” para “agarrou”, “cosca” para “cócega”). Também é válido ressaltar que uma estratégia ubíqua na tradução de Britto é a compensação: aqui, os desvios gramaticais na fala de Joe não estão sobre as mesmas palavras do original, mas isto pouco afeta o efeito estilístico geral. Finalmente, passemos para o discurso de Magwitch no capítulo 42.

And when it come to character, warn't it Compeyson as had been to school, and warn't it his schoolfellows as was in this position and in that, and warn't it him as had been know'd by witnesses in such clubs and societies, and nowt to his disadvantage? And warn't it me as had been tried afore, and as had been know'd up hill and down dale in Bridewells and Lock-Ups? And when it comes to speech-making, warn't it Compeyson as could speak to 'em wi' his face dropping every now and then into his white pocket-handkercher-ah! and 'wi' verses in his speech, too-and warn't it me as could only say, 'Gentlemen, this man at my side is a most precious rascal'?

(DICKENS 1929: 365)
E quanto ao caráter, não era o Compeyson que tinha estudado em escola, e que tinha colega ocupando cargo aqui e ali, e não era ele que tinha sido visto pelas testemunha nesse clube e naquela sociedade, e nunca fazendo nada de errado? E não era eu que já tinha sido julgado, e era muito bem conhecido em tudo que era prisão e xilindró? E em matéria de fazer discurso, não era o Compeyson que sabia falar com eles, escondendo o rosto naquele lenço branco de vez em quando - ah! e recitando verso também no meio da fala dele - e não era eu que só sabia dizer: 'Senhores, este homem ao meu lado é um pulha descarado'?

(DICKENS 2012: 302) 
Mais uma vez, a tradução de Britto foi a única das três analisadas em que houve preocupação com a manutenção das marcas das variantes, ora por meio de desvios da gramática ("pelas testemunha"), ora por meio de palavras ou sintagmas próprios da coloquialidade ("xilindró", "tudo que era", "pulha”). Assim, pode-se dizer que seu princípio de traduzir o "marcado pelo marcado" parece de fato ter orientado sua tradução de Dickens.

\section{Conclusão}

Feitas algumas considerações iniciais acerca da presença de variantes na literatura (seção 1) e da questão do eye dialect, recurso gráfico bastante utilizado por Dickens e na literatura inglesa de forma geral, passamos pelas considerações de John Milton a respeito do apagamento sistemático de variantes em traduções brasileiras de romances clássicos empreendidas pelo Clube do Livro; em seguida, comentamos a presença das variantes no romance Great Expectations e analisamos as soluções de três tradutores (BernardDerosne, Morais e Britto) com respeito a essa dificuldade. Concluímos que tanto as traduções de Bernard-Derosne quanto as de Morais apagam completamente o uso das variantes, produzindo um efeito de homogeneização que apaga elementos importantes do romance, ao passo que Britto, pelo contrário, orientado pelo princípio de Henri Meschonnic ${ }^{7}$ segundo o qual se deve traduzir o "marcado pelo marcado", esforça-se em manter as distinções de registro existente nas falas das personagens originais, obtendo muitas vezes resultados bastante felizes.

\section{Referências}

Berman, A. A Tradução e a Letra ou o Albergue do Longínquo. Rio de Janeiro: 7Letras/PGET, 2007.

BRETT, D. F. "Eye dialect: translating the untranslatable". Annali della Facoltà di Lingue e Letterature Straniere di Sassari, v. 6, 2009, p. 49-62.

\footnotetext{
${ }^{7}$ Conforme se viu nos trechos citados de $A$ Tradução Literária.
} 
BRITTO, P. H. A tradução literária. Rio de Janeiro: Civilização Brasileira, 2012.

Colvin, S. "Aristophanes: Dialect and Textual Criticism". Mnemosyne. Leiden, v. 48, n. 4, 1995, p. 34-47.

DiCKens, C. Grandes Esperanças. Tradução de Armando de Morais. São Paulo: Círculo do Livro, 198?.

- Grandes Esperanças. Tradução de Paulo Henriques Britto. São Paulo: Cia. Das Letras, 2012.

. Great Expectations. New York: P. F. Collier and Son, 1929.

- Les Grandes Espérances. Tradução de Bernard Derosne. Paris: Hachette, 1889. Disponível em:

<https://fr.wikisource.org/wiki/Les_Grandes_Espérances>. Acesso em: 19 out. 2017.

- Oliver Twist. Tradução de Antônio Ruas. São Paulo: Círculo do Livro, 197?.

LANE-MerCIER, G. Translating the untranslatable: The Translator's Aesthetic, Ideological and Political Responsibility. Target, Amsterdam, v. 9, n. 1, 1997, p. 43-68.

MiLton, J. "The Translations of O Clube do Livro". TradTerm, São Paulo, n. 3, 1996, p. 47-65.

PukKari, M. "The Purpose of Dialect in Charles Dickens's Novel Great Expectations". Bachelor's seminar and thesis (682285A), English philology, Faculty of Humanities, University of Oulu, 2015. Disponivel em: $\quad$ http://jultika.oulu.fi/files/nbnfioulu-201602031111.pdf.> Acesso em: 19 out. 2017.

PyM, A. "Translating linguistic variation". In Vega, M. A.; Martín-Galtero, R. (ed.): Traducción, metrópoli y diáspora. Madrid: Universidad Complutense de Madrid, 2000. p. 69-75.

Ramos, G. Vidas Secas. Rio de Janeiro: Record, 2011.

TÁPIA, M. Ao que se dá o tradutor de poesia?, Eutomia, Recife, v. 10, n. 1, Dez. 2012, p. 49-62.

Recebido em: 05/12/2019

Aceito em: 27/05/2020

Publicado em junho de 2020 